\title{
LA CONSTRUCCIÓN DE VALOR COMO SUMATORIA DE CAPACIDADES, EN LA INCERTIDUMBRE QUE GENERA EL COVID 19
}

\author{
Amigo, Adriana \\ Arcieri, Hernán Carlos \\ Perozzi, Alberto Ramón
}

\section{Resumen:}

La ecuación del valor es la relación entre los requerimientos de los clientes, las expectativas de los clientes y la oferta de la empresa. Esa construcción de valor basada en el equilibrio entre esos tres miembros de la ecuación, se ha visto alterada profundamente ante la declaración de pandemia mundial por parte de la OMS. El desafío empresarial será formular, implementar y controlar una nueva construcción en donde se determine el estado de los requerimientos actuales de los mercados frente a sus expectativas, lo que generará un oferta de la empresa distinta, única, comprometida la que deberá ser puesta a prueba en el antes, el durante y el después, pues los requerimientos de los mercados finales e industriales se habrán visto alterados ante la presencia de un enemigo común, contra el que sólo se puede actuar desde la prevención y desde el aislamiento. En esas circunstancias, muchos mercados se han vistos transformados y la comunidad científica deberá ser el aval de la confiabilidad de las marcas

Palabras claves: Ecuación - Valor - Requerimientos - Expectativas - Comunidad Científica - Confiabilidad

\section{Abstract:}

The value equation, is the relationship between Customer requirements, Customer expectations, and the company's. This construction of value, base don the balance between these three members of the equation, has been profoundly altered by the declaration of a global pandemic by the WHO. The business challenge, will be to formulate, implement and control a new construction where the state of the current requirements of the markets, is determined against their expectations, which will generate a different, unique, committed company offer which must be tested in the before, during and after, since the requirements of the final and industrial markets will have been altered in the presence of a common enemy, against which actios can only be taken from prevention and isolation. Under these circumstances, many markets have been transformed and the scientific community must be the guarantee of the trusworthiness of the brands. 
Keywords: Equation - Value - Requirements - Expectations - Scientific - Community - Trisworthiness

\section{INTRODUCCION}

La crisis económica generada por la enfermedad del coronavirus (COVID-19) tiene un impacto importante en los países de América Latina y el Caribe y golpea una estructura productiva y empresarial con debilidades que se han originado a lo largo de décadas.

Para tomar dimensiones de ello, la brecha externa de productividad medida por la CEPAL, en 1980 la productividad laboral latinoamericana alcanzaba el 36,6\% de la de los Estados Unidos. Después de una abrupta caída en esa década y, en menor medida, en los años noventa, la productividad relativa de la región llegó a ser de apenas un quinto de la de los Estados Unidos entre 1999 y 2018. En términos absolutos, la productividad laboral de la región creció un 0,6\% anual entre 2008 y 2018.

En cuanto a la brecha interna, la heterogeneidad entre las empresas es muy elevada en América Latina. En 2016 la productividad del trabajo de una empresa mediana era, en promedio, menos de la mitad de la correspondiente a una empresa grande. En las empresas pequeñas la productividad laboral alcanzaba apenas al $23 \%$ de la productividad de una empresa grande y las microempresas presentaban una productividad laboral equivalente a solo un $6 \%$ de la correspondiente a las empresas grandes.

Es muy difícil prever la intensidad y la duración de la crisis actual. Sin embargo, es posible identificar algunas de sus especificidades. Es un fenómeno global.

No existen vacunas ni remedios eficaces, la única manera de controlar la pandemia es mediante diferentes niveles de restricción social y, por lo tanto, de limitación de actividades económicas. De un primer momento de emergencia, se pasará una segunda fase donde haya que "convivir" con el virus y luego se pasará a una nueva realidad económica y social. Esa realidad será distinta en cada país según la duración e intensidad de las dos primeras etapas, las medidas económicas y sociales que se hayan tomado y las capacidades institucionales, productivas y tecnológicas acumuladas. La crisis económica tiene su origen tanto en la oferta como en la demanda, y la combinación de estos efectos ha tenido intensidades distintas en los diferentes sectores. 


\section{GRÁFICO 1. INTENSIDAD DE LOS EFECTOS DE LA CRISIS, POR SECTOR DE ACTIVIDAD ECONÓMICA. Fuente. CEPAL (2020)}
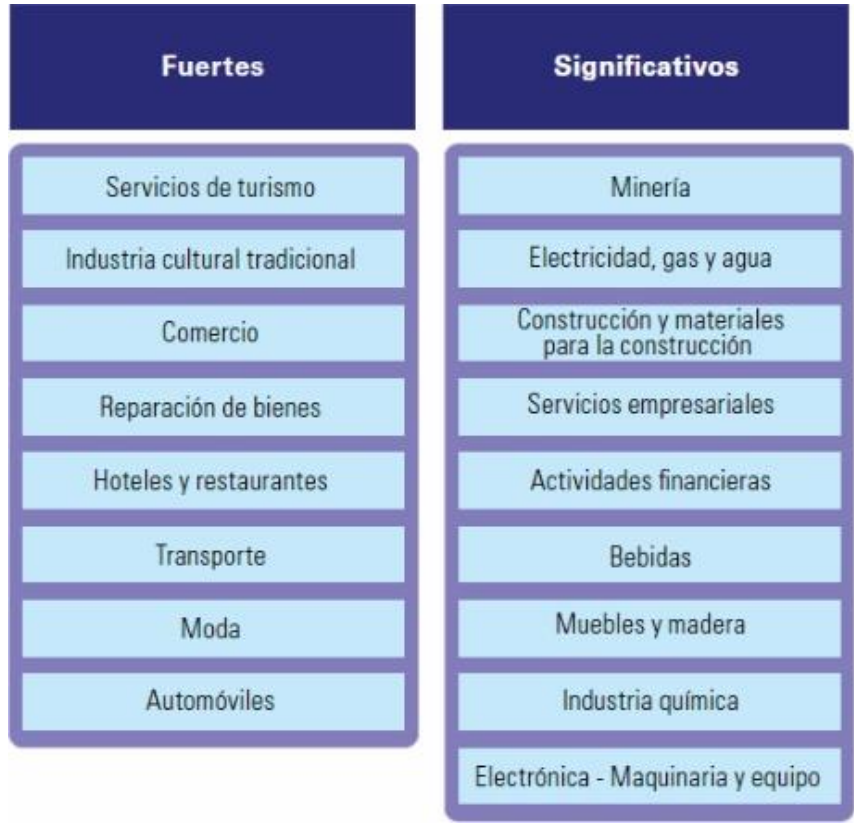
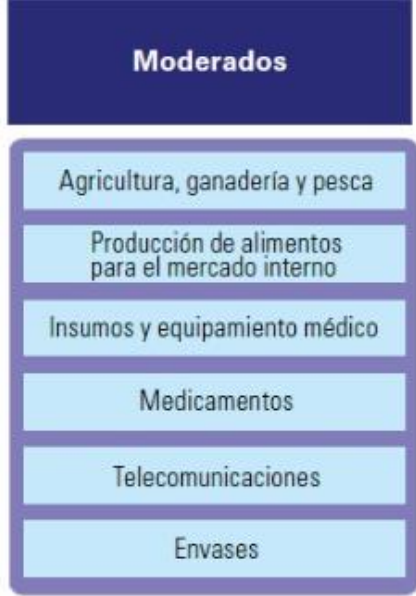

Fuente: Comisión Económica para América Latina y El Caribe (CEPAL) (2020)

Sobre la base de esta clasificación según la intensidad de los efectos de la pandemia, la Comisión Económica para América Latina y el Caribe (CEPAL) estima que un 34,2\% del empleo formal y un $24,6 \%$ del PIB de la región corresponden a sectores fuertemente afectados por la crisis derivada de la pandemia. Más aún, menos de la quinta parte del empleo y del PIB se generan en sectores que serían afectados solo de forma moderada.

\section{GRÁFICO 2. AMÉRICA LATINA Y EL CARIBE (27 PAÍSES): PIB Y EMPLEO CORRESPONDIENTES A LOS DISTINTOS SECTORES SEGÚN INTENSIDAD DEL IMPACTO ESPERADO DE LA CRISIS. (EN PORCENTAJES) Fuente: CEPAL. 2020.}

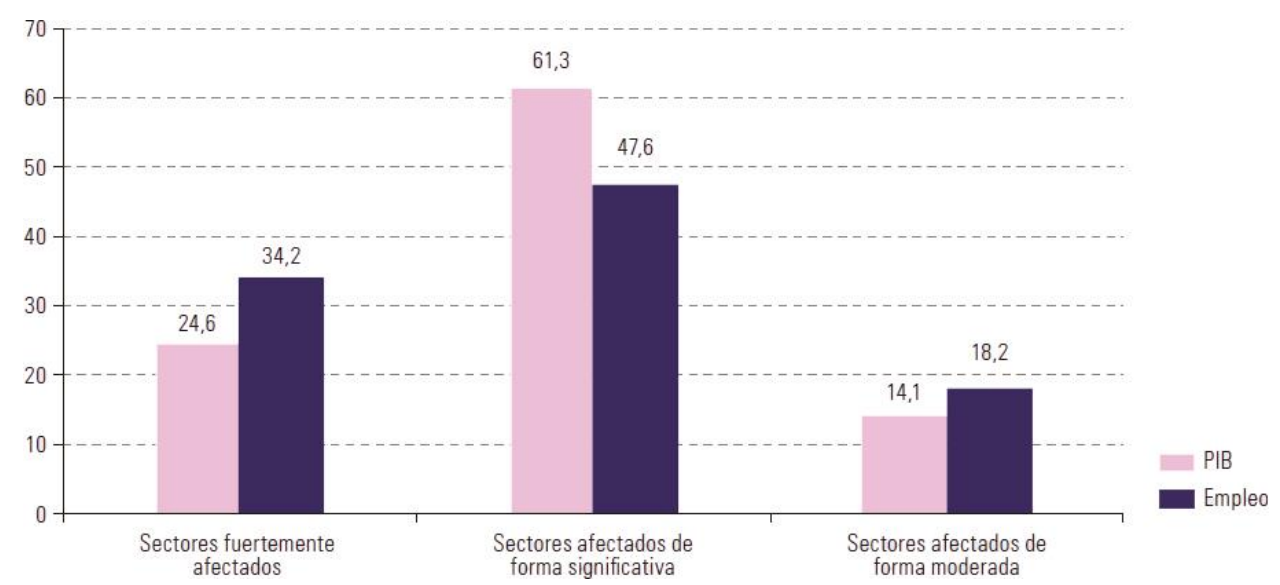

Fuente: Comisión Económica para América Latina y El Caribe (CEPAL) (2020) 
La crisis golpea con mayor intensidad a los sectores industriales potencialmente de mayor dinamismo tecnológico y, por lo tanto, profundizará los problemas estructurales de las economías de la región. Esto significa que, si no se implementan políticas adecuadas para fortalecer esas ramas productivas, existe una elevada probabilidad de que se genere un cambio estructural regresivo que conduciría a la reprimarización de las economías de la región.

El impacto sobre la estructura industrial ya se puede observar en algunos países, al analizar el desempeño del primer cuatrimestre de 2020 comparado con el del mismo período de 2019.

En la Argentina, la producción industrial disminuyó un 13,5\% y los sectores de automóviles $(-40,4 \%)$, autopartes $(-37,8 \%)$, motocicletas $(-56,2 \%)$ y equipos eléctricos $(-41,6 \%)$ presentaron resultados aún peores. También algunos sectores intensivos en trabajo sufrieron caídas muy superiores al promedio de la industria; por ejemplo, los sectores de textiles $(-27,4 \%)$, prendas $(-37,7 \%)$ y calzado $(-40,3 \%)$. En cambio, el rubro de alimentos y bebidas creció un 1,5\%.

Se pronostica un cierre masivo de empresas, la gran mayoría de las empresas de la región han registrado importantes caídas de sus ingresos y presentan dificultades para mantener sus actividades: tienen serios problemas para cumplir con sus obligaciones salariales y financieras, y dificultades para acceder a financiamiento para capital de trabajo.

En la Argentina, el 44\% de las empresas industriales no tenían liquidez para pagar el $50 \%$ de los salarios de abril (un $12,3 \%$ no pudo pagar la nómina); el $38 \%$ no pudo pagar servicios públicos; el $48 \%$ no pudo pagar a sus proveedores, y el 57\% no pagó los impuestos (UIA, 2020).

Aunque la crisis afecta a todas las empresas, el impacto será mucho mayor en el caso de las microempresas y las pymes.

Sobre la base de los diagnósticos de las cámaras empresariales en relación con la situación de las mipymes y de las características de la crisis, la CEPAL estima que cerrarían más de 2,7 millones de empresas formales en la región, con una pérdida de 8,5 millones de puestos de trabajo.

El impacto será muy diferente según el sector y el tipo de empresa. 


\section{GRÁFICO 3. AMÉRICA LATINA Y EL CARIBE (27 PAÍSES): EMPRESAS QUE PODRÍAN CERRAR COMO CONSECUENCIA DE LA CRISIS, SEGÚN SECTOR (EN NÚMERO) Fuente. CEPAL 2020.}

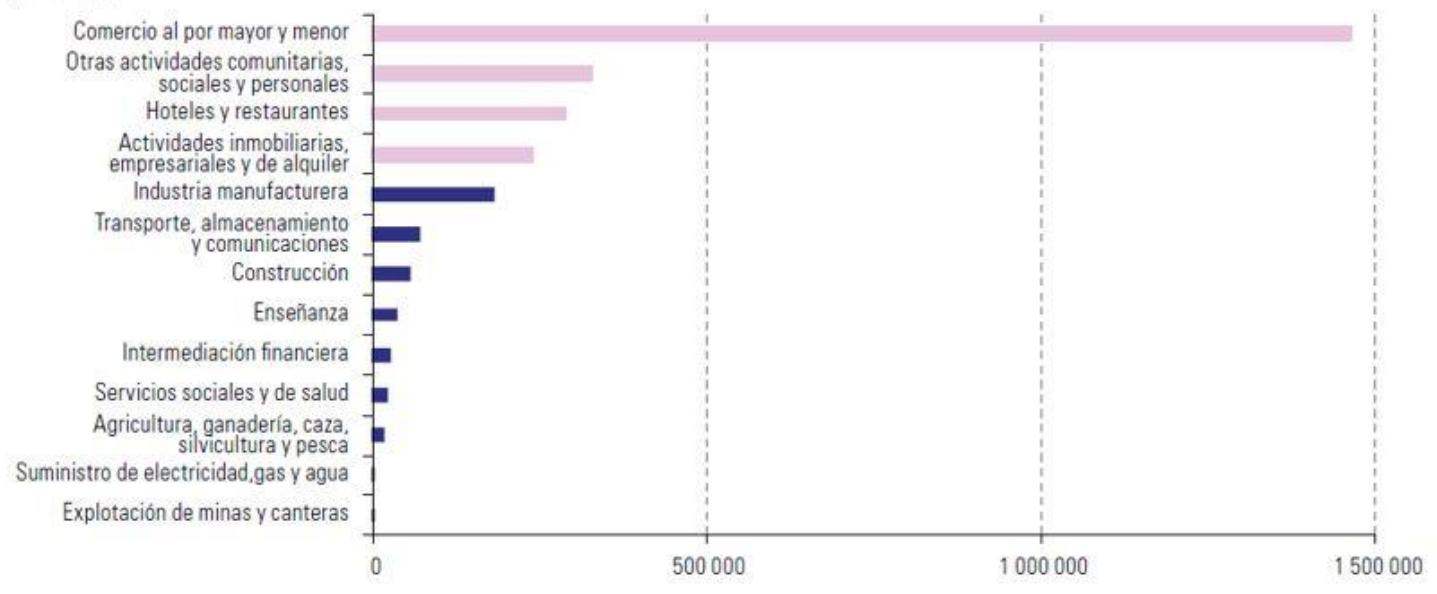

Fuente: Comisión Económica para América Latina y EI Caribe (CEPAL)

\section{OTROS DATOS IMPACTANTES}

Al comienzo del aislamiento, por abril de este año, la proyección del Banco de Francia, ya provocaba escalofríos, pronosticaba el desplome del $6 \%$ del PBI de Francia. Es la caída dos veces más fuerte que la de la crisis del 2008/2009.

El Instituto de Estadística de Francia, estima que la recesión, parate, frenazo a la economía, se traduce en una contracción del $3 \%$ del PBI por mes. Hasta el 3 de abril de este año, de 3.600.000 a 5.000.000 de asalariados de dicho país, estaban en paro parcial, una cifra nunca vista ni experimentada antes.

Para el resto de los países europeos, es igual o peor. El Instituto Alemán de Coyuntura, IFO, afirmaba que una prolongación del paro parcial, después de tres meses, podría traducirse en una caída del $10 \%$ al $18 \%$ del PBI.

Para Reino Unido, España, Alemania, ya se esperaba por entonces, una caída del PBI superior al $6 \%$ y en Italia superior al 8,2\%.

Por abril de este año, la CEPAL, el FMI y el Banco Mundial vaticinaron una caída en América Latina y en el Caribe del 5, $3 \%$ del PBI, lo que se vería reflejado en mayor desempleo, aumento de la pobreza y baja del consumo.

El otro mapa de la pandemia, lo representó el petróleo. Hoy cabría preguntarnos, de quién es hoy el negocio del petróleo, de los que compran, de los que venden o de los que lo guardan?: Los cargueros petroleros, fueron los grandes beneficiados. 
En EEUU, un epidemiólogo de la Casa Blanca, Anthony Fauci, hablaba del riesgo de abrir la economía, aún con 10.000 .000 de desempleados en dos semanas de abril último.

COFACE, el organismo asegurador de las exportaciones francesas, publicaba por entonces, una primera evaluación de la crisis, en la que estimaba que 68 países, vivirían este año la recesión más importante de los últimos años en la que los más afectados serían los países más industrializados.

Todo lo vaticinado, no solamente ocurrió, sino que se profundizó en progresiones geométricas. Esta crisis mundial, estuvo transversalmente marcada por cuatro variables:

- La intensidad del desplome

- La rapidez

- La desaparición de los mercados de consumo tradicionales

- El coronavirus es hoy la principal preocupación, lo que genera el cambio de memoria afectiva e impulsiva en los generadores de hábitos de consumo tradicional.

Estas realidades, tan difíciles como imprevisibles, nos plantean un nuevo horizonte en el proceso de construcción de valor para los clientes, con el objetivo de re direccionar y desarrollar nuevos vínculos estables sobre los que soportar la ventaja competitiva sostenible.

\section{QUÉ FUE LA GLOBALIZACIÓN}

Se decía de la globalización que "era uno de los principales factores que afectaban a (...) las organizaciones. Los gerentes de organizaciones grandes y pequeñas enfrentaban el reto de un ambiente externo de competencia y mercados globales crecientes. (Robbins y Coulter. 1995:69)

Con la globalización se pretendió abrir el comercio y derribar las barreras geográficas que separaban a los países. Pero la apertura significaba, justamente, abrirse a lo malo tanto como a lo bueno. De Filipinas a Inglaterra, de Israel a Pakistán, organizaciones y empleados corrían el riesgo de sufrir ataques terroristas. Otro problema de la apertura era la interdependencia económica de las naciones que comerciaban. Si la economía de un país vacilaba, podía producir un efecto de fichas de dominó en otros países con los que comerciaba."(Robbins y Coulter. 2005:93)

Pero nadie pensó ni se imaginó, siquiera en una profecía, que lo malo de la globalización vendría de la mano de un virus que apareció por primera vez en diciembre de 2019, en la ciudad China de Wuhan, ubicada a las orillas del río Yangtsé, 
y que a través de su puerto, aeropuerto y su red ferroviaria se diseminó con una velocidad inusitada al resto del mundo.

“... La discontinuidad es tan frecuente como la continuidad, por lo cual no se puede confiar en que lo que pasó ayer pasará mañana del mismo modo. Estamos viviendo en otra condición de incertidumbre continua, permanente. (...) la incertidumbre es la única certeza que tenemos."

"... la llamada futurología es un fraude porque no puede existir ciencia sobre la nada, y el futuro no existe (...). Cuando el futuro se vuelve realidad, ya no es más futuro: es presente" (http://www.perfil.com/internacional/zygmunt-bauman-ser-populista-no-es-siempre-

malo.phtml. (9-1-17)"

La pandemia se desplazó como una mancha venenosa cubriendo todo el planeta sin dejar lugar por afectar; al 13 de septiembre de 2020 se habían informado más de 28 millones de casos de la enfermedad en 218 países del mundo.

$\mathrm{Ni}$ una sola medida preventiva o contingente de ninguna organización pública o privada, con o sin fines de lucro había sido prevista para afrontar un desafío de esta magnitud que la naturaleza había reservado a la humanidad del siglo 21.

El impacto de la pandemia, sin lugar a dudas, ha resultado mayor que la crisis de 1929, el alcance y sus consecuencias, aún no pueden cuantificarse.

La pandemia afectó por igual, casi democráticamente, a países como a empresas, sin distinguir entre pobres y ricos.

Lo que no hay duda es que las relaciones y la dinámica de los negocios no serán las mismas que en la pre-pandemia. En esta situación el cambio es lo único estable y como en toda crisis se abren nuevas oportunidades, las que solo serán aprovechadas por aquellas organizaciones que interpelen la nueva realidad, la analicen y se adapten rápidamente al nuevo escenario; las que no lo hagan, desaparecerán.

En este trabajo se abordarán de qué manera la pandemia introdujo disrupciones en algunas dimensiones del desempeño organizacional. Se trabajará sobre el ambiente, la cultura y el poder organizacional y cómo se vieron afectados.

\section{AMBIENTE EXTERNO}

El término ambiente externo se refiere a las fuerzas e instituciones fuera de la organización que pueden influir en su desempeño. El ambiente externo está formado por dos componentes: el entorno específico y el general (Robbins y Coulter. 2005: 64)

Según Robbins y Coulter (2005; 68) el entorno específico abarca las fuerzas externas que tienen efecto directo $\mathrm{e}$ inmediato en las decisiones y actos de los directivos y que son pertinentes para la consecución de las metas de la organización, entre ellos se puede distinguir a los clientes, proveedores, competencia y grupos de presión El 
entorno general, en cambio, comprende las condiciones externas generales que pueden incidir en la organización (condiciones económicas, legales, políticas, tecnológicas, socioculturales, demográficas y mundiales)

Los cambios que se produjeron en el comportamiento de los consumidores fue notable, cambios en las preferencias de los productos y servicios demandados generó que actividades hasta entonces muy demandadas como turismo o actividades culturales fueran directamente no utilizadas, provocando el cierre de miles de organizaciones dedicadas a estas actividades con el consiguiente despido masivo de trabajadores. Asimismo, otras ramas de la actividad incrementaron notablemente la cantidad de consumidores aumentando el valor de sus acciones, así encontramos en el mismo segmento del entretenimiento a las plataformas virtuales Netflix o Amazon que vieron incrementada la demanda de sus servicios. Los cambios han sido brutales.

Se puede observar también, analizando la competencia, como aquellas organizaciones que habían apostado e invertido en la incorporación de tecnologías de la información, robotización, big data, servicios logísticos y de comunicación se adaptaron mucho mejor y más rápidamente a la nueva situación, generando valor para sus empresas en detrimento de aquellas que o no invirtieron en estas tecnologías o bien se encontraban en un estadio anterior y no lograron revertir la situación.

Los grupos de presión también se encontraron activos en esta etapa, grupos integrados por personas que presionaron para que muchas actividades se cerraran para evitar la propagación del versus como otros grupos que luchaban por la apertura de las actividades y morigerar el efecto sobre la actividad económicas; toda esta puja afectó el desempeño organizativo de muchas organizaciones (clubes, teatros, gimnasios, instituciones educativas y culturales, etc.)

Jamás en la historia de la humanidad se había sentido tan nítidamente el impacto que la tecnología y la globalización tienen sobre el mundo actual. Desde la inmediata diseminación del virus por todo el orbe a causa de la interdependencia que se produce por las comunicaciones de todo tipo (terrestre, marítima y aérea) como la dependencia de la tecnología de la información y comunicación para reaccionar ante la imposibilidad de desplazamiento de las personas y los bienes. Ésta dio respuestas a través del desarrollo logístico, la provisión de redes y plataformas virtuales utilizadas para comunicarse y trabajar desde lugares remotos, o desde el ámbito de la medicina para desarrollar en tiempo record (según las estimaciones) una vacuna para terminar con la pandemia.

El entorno afecta a los directivos por su grado de incertidumbre y por las relaciones entre la organización y las partes externas interesadas. 
No todos los ambientes son iguales, sino que difieren por su grado de incertidumbre ambiental, que es la medida de los cambios y la complejidad del entorno de una organización (Robbins y Coulter. 2005: 68-69).

Si construyéramos una matriz con la incertidumbre ambiental que afecta a la mayoría de las organizaciones durante la pandemia, sin dudas la ubicaríamos dentro del cuarto cuadrante con las características que pueden observarse en la misma.

\section{GRÁFICO 5. MATRIZ CAMBIO COMPLEJIDAD}

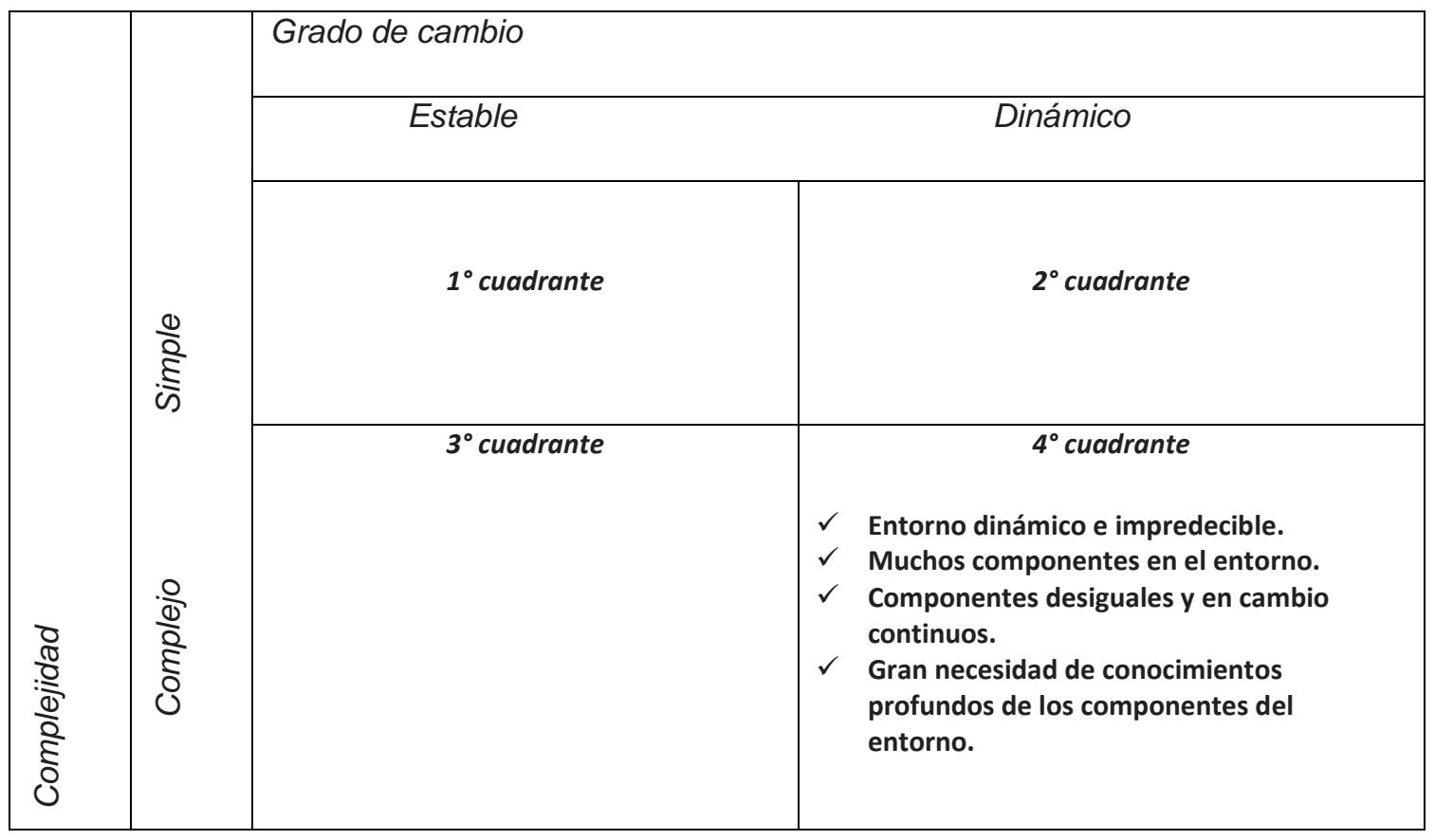

\section{CULTURA ORGANIZACIONAL}

La cultura es a las organizaciones lo que la personalidad es a las personas.

Para Schein la cultura es "un patrón de supuestos básicos compartidos que el grupo aprende en la medida que resuelve sus problemas de adaptación externa e integración interna, que los ha trabajado lo suficiente para ser considerados como válidos y, por lo tanto, dignos de ser enseñados a los nuevos miembros como la forma correcta de percibir, pensar y sentir en relación con esos problemas" (1992: 12).

Sobre la base del concepto anterior, este autor propone tres niveles para su análisis, donde nivel se refiere al grado en que el fenómeno cultural es visible al observador (Schein 1992: 16): Artefactos, valores adoptados y declarados y supuestos básicos (Schein, 1992: 16-27).

La pandemia vino a modificar en cada organización estos tres niveles, modificando de esa forma la cultura hasta aquí reproducida. 
En cuanto a los artefactos, apenas alguien ingresaba a una organización distinguía la vestimenta, los colores, el mobiliario. Después de la pandemia los artefactos que captan la mirada del observador son los barbijos, las máscaras; en lugar de floreros con flores, los potes de alcohol en gel; escritorios y mostradores separados por pantallas acrílicas, escritorios aislados, etc.

En relación a los valores adoptados y declarados se pueden observar los protocolos rígidos para operar durante la pandemia, el home office, el reemplazo de las reuniones presenciales por reuniones a través de plataformas virtuales.

También se observan cambios notorios en los rituales organizacionales, el saludo a través de un beso o un apretón de manos fue reemplazado por un toque de codos o de puños, ya no se festejan los cumpleaños en las oficinas y no se realizan los "after office" habituales a la salida de las mismas. Las oficinas que estaban abiertas hoy permanecen cerradas y cada vez que un empleado se acerca a otro existe un grado de desconfianza mutua, pensando que pueda estar contagiado

Supuestos básicos inalterables por décadas fueron derrumbados de un plumazo, un ejemplo gráfico lo constituye la enseñanza, donde la presencialidad era hasta entonces un valor arraigado e indiscutible y la educación virtual una excepción, sin embargo, ésta última pasó a ser la regla y la presencialidad no se sabe cuándo regresará y si lo hará de la misma forma que en el pasado.

Muchos aspectos de la vida y la cultura de las instituciones han sido puestos en discusión, tanto en organizaciones con culturas fuertes como débiles. Pasada la pandemia nada volverá a ser como antes y muchos aspectos culturales serán reconsiderados y reconfigurados. Se abre una buena oportunidad de cambio para aquellas organizaciones que así lo decidan.

\section{RELACIONES DE PODER}

Poder es la capacidad de un departamento en una organización para influir en otras personas o departamentos a fin de producir los resultados deseados. Es el potencial de influir en otros dentro de la organización, con la meta de lograr los resultados deseados por quienes tienen el poder. (Daft, 2010: 497)

Desde una versión marxista, el poder tiene que ser analizado como algo que circula, 0 más bien, como algo que no funciona sino en cadena. No está nunca localizado aquí o allí, no está nunca en las manos de algunos, no es un atributo como la riqueza o un bien (...) el poder transita transversalmente, no está quieto en los individuos (Foucault, 1992: 146)

También se deben distinguir distintos tipos de poder individual dentro de las organizaciones y uno de ellos es el poder experto. Daft lo define como aquel que 
deriva de la mayor capacidad o el mayor conocimiento de una persona acerca de las tareas que se desempeñan. (2010: 498)

"Centralidad de la red significa tener una ubicación central en la organización y acceso a la información y a las personas que son cruciales para el éxito de la empresa. Los gerentes, así como los empleados en el nivel inferior, son más efectivos y tienen más influencia cuando se colocan en el centro de una red de comunicaciones, desarrollando conexiones con las personas en toda la empresa. (Daft.2010: 501) Con la pandemia se ha visto claramente como el "control de la información también puede ser una fuente de poder. Los gerentes reconocen que la información es un recurso de negocios importante y que, al controlar qué información se recaba, cómo se interpreta y se comparte, pueden influir en cómo se toman las decisiones. En muchas de las empresas actuales, la información se comparte ampliamente, lo que incrementa el poder de las personas en toda la organización. (Daft.2010: 500)

Con la enfermedad empezaron a aparecer como voceros de muchas organizaciones a personas o grupos de personas que habitualmente no eran, hasta entonces, los encargados de ser los representantes o voceros. Esto se dio tanto a nivel privado como a nivel estatal. Comenzaron a ser centrales dentro de las instituciones los responsables de los servicios médicos, higiene y seguridad, infraestructura de sistemas informáticos y logística. Si alguien dibujara hoy la red de una organización seguramente muchos de estos actores o grupos ocupan un lugar central en la red organizacional, dado que son los que pueden reducir la incertidumbre que afecta a la organización son consultados por todos los miembros de la institución. A nivel del Estado los epidemiólogos han ocupado ese centro.

¿Cuáles fueron las causas que empoderaron a estas personas o grupos, muchas veces no respaldada del poder legítimo que otorga la autoridad formal, representado en la escala jerárquica de la organización?

Varias son las razones que justifican este desplazamiento del poder hacia estos grupos. La primera de ellas es la posesión de un poder experto basado en el conocimiento sobre cuestiones médicas y de salud pública; manejo de redes y plataformas virtuales, nuevos sistemas de comunicación y de nuevas tecnologías relacionadas con e-commerce y ventas por Internet. En segundo lugar, las nuevas necesidades planteadas por las nuevas formas de logística y distribución de los bienes y servicios necesarios para la totalidad de las organizaciones para continuar operando.

\section{AISLAMIENTO POR COVID 19. ¿QUÉ SENTIMIENTOS GENERA?}

Sebastián Corso, de la División Insights de Kantar, expresa, que frente a una situación sin precedentes, se empiezan a gestar cambios de hábitos, con consecuencias 
impredecibles, lo que obliga a las marcas a ejercitar la empatía y la capacidad de dar respuestas rápidas y convincentes. (Corso, 2020).

Según el estudio realizado por Kantar, a nivel mundial, Barómetro COVID 19, se llegó a la conclusión de que los argentinos han modificado su conducta, principalmente en determinados aspectos:

- La principal preocupación es la salud, ante la amenaza invisible que genera el coronavirus.

- Conciencia de la vulnerabilidad y finitud de la vida, preponderantemente en la franja etárea > 55 años, en el $67 \%$ de la muestra analizada.

- A 90 días de la pandemia, las clases medias altas manifestaban menor preocupación por la situación, con tendencia a justificar la flexibilización "auto administrada"

- Se modificaron los patrones de consumo de medios de comunicación, tanto para informarse como para entretenerse

- El impacto transversal de las redes sociales, convertidas en fuentes de tutoriales de actividades en el hogar.

- Se manifestaron sentimientos y sensaciones tales como: Miedo; Angustia; Vulnerabilidad; Falta de previsión; Inseguridad sobre el futuro; Cambios en el humor

- Según el estudio realizado por Kantar, a nivel mundial, se llega a la conclusión de que las personas, en especial los Argentinos, han modificado la conducta, principalmente en determinados aspectos:

- Valor de Uso: Cambia lo que se compra y cómo se compra

- Valor de Cambio: El consumidor hoy prioriza sus pagos y posterga los gastos superfluos.

Según el análisis de la BCG, (2020) los cambios fueron profundos en el comportamiento y sus ramificaciones:

- Más tiempo en casa

- Mayor énfasis en higiene y salud

- Mayor preocupación por la seguridad familiar

- Cambios en el trabajo, desde el lugar original al trabajo remoto

- Racionalización de actividades y operaciones

- Descentralización de cadenas de suministros y distribución

- Preparación ante la crisis: sistemas de rescilencia formales e informales

- Todos estos cambios han generado múltiples consecuencias, como las observamos en el siguiente gráfico: 
GRÁFICO 6. ANÁLISIS DESCRIPTIVO BCG Fuente (Amigo, 2020)

\begin{tabular}{|c|c|c|c|}
\hline $\begin{array}{c}\text { Cambios de } \\
\text { hábitos }\end{array}$ & $\begin{array}{c}\text { Modificación de patrones } \\
\text { de uso de medios } \\
\text { comunicación: I+E } \\
\text { Streaming }\end{array}$ & $\begin{array}{c}\text { Redes sociales, como } \\
\text { factor de } \\
\text { acercamiento a } \\
\text { afectos }\end{array}$ & $\begin{array}{c}\text { Compras en negocios de } \\
\text { proximidad }\end{array}$ \\
\hline $\begin{array}{c}\text { Home office } \\
\text { LIVE }\end{array}$ & Énfasis en Higiene y Salud & $\begin{array}{c}\text { Eating at home } \\
\text { Take away } \\
\text { E-Payments } \\
\text { Home Cooking } \\
<\text { Eating out } \\
>\text { Food delivery }\end{array}$ & $\begin{array}{c}\text { Bussiness Travel No } \\
\text { Personal Travel, se está } \\
\text { iniciando el turismo local }\end{array}$ \\
\hline
\end{tabular}

Inmediatamente antes de la pandemia, ¿Cuál era el vínculo de las marcas con los clientes?

Los vínculos con los clientes, se basaban en los movilizadores del placer y de la satisfacción corto placista.

GRÁFICO 7. MOVILIZADORES DE PLACER. Fuente. Amigo, 2020

\begin{tabular}{|l|l|}
\hline Movilizadores de placer & \multicolumn{1}{|c|}{ Impactos en las conductas comportamentales } \\
\hline Esporádicos & $\begin{array}{l}\text { Consumos irresponsables y en respuesta a estímulos corto } \\
\text { placistas, como campañas promocionales funcionales a } \\
\text { empresas y no a la persona }\end{array}$ \\
\hline $\begin{array}{l}\text { Pérdida de identidad de la } \\
\text { persona }\end{array}$ & Sobre la construcción de la identidad de la marca \\
\hline $\begin{array}{l}\text { Generadores de } \\
\text { insatisfacción }\end{array}$ & Consumo individual e irreflexivo \\
\hline
\end{tabular}

¿Qué cambios opera, el aislamiento social por el Covid 19 en los consumidores?

GRÁFICO 8. MOVILIZADORES DE UNIÓN. Fuente. Amigo, 2020

\begin{tabular}{|l|l|}
\hline \multicolumn{1}{|c|}{ Movilizadores de unión } & \multicolumn{1}{|c|}{ Impactos en las conductas comportamentales } \\
\hline Estructurales y profundos & $\begin{array}{l}\text { Consumos responsables, en los que el principal círculo de } \\
\text { influencia social pasa a ser el hogar y la familia }\end{array}$ \\
\hline $\begin{array}{l}\text { Fortalecimiento de } \\
\text { identidad de la persona }\end{array}$ & Sobre la pérdida de la identidad de la marca \\
\hline $\begin{array}{l}\text { Generadores de } \\
\text { satisfacción }\end{array}$ & Consumo individual, familiar y reflexivo \\
\hline
\end{tabular}


En situaciones normales, podríamos haber afirmado que estas transformaciones comportamentales, deberían haber operado en transcurso de períodos largos y cíclicos, por lo menos en décadas, sin embargo, estos cambios operaron en muy poco tiempo, generando transformaciones rápidas, profundas y sísmicos, ¿Vinieron para quedarse?

\section{GRÁFICO 9. CAMBIOS COMPORTAMENTALES FUENTE Amigo, 2020}

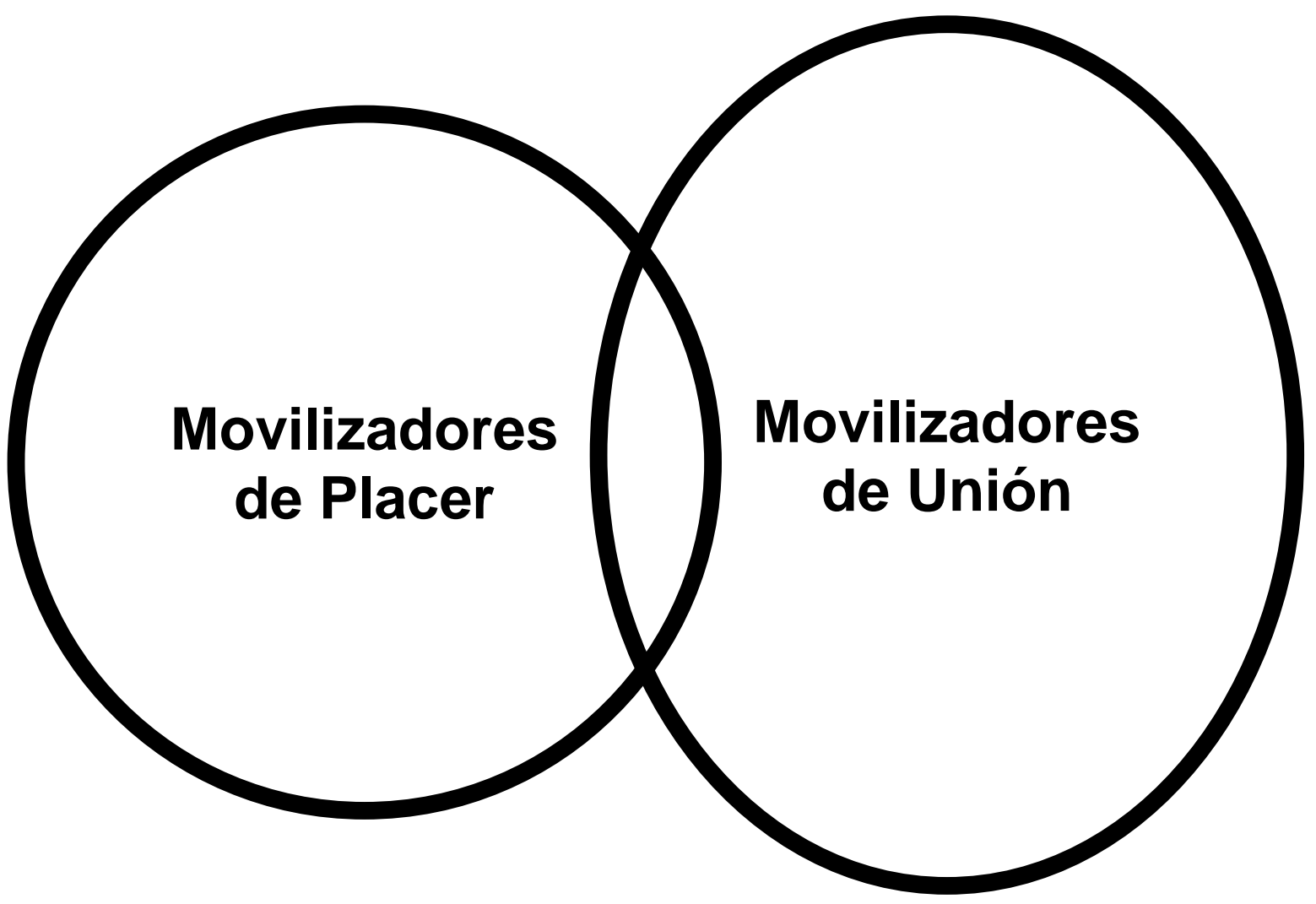

Vemos en la figura, que el horizonte generado por los movilizadores de placer, constituye para las marcas, un escenario de menor dimensión en cuanto a su control, mientras que los movilizadores de unión le significarán a las marcas dimensiones incontrolables, en cuanto a conductas, requerimientos, expectativas, en las que el valor de marca, se pondrá en tela de juicio y el proceso de generación de ventajas competitivas sostenibles, deberán equilibrar y monitorear la ecuación de los tres términos del valor: 
GRÁFICO 10. LA ECUACIÓN DEL VALOR. Fuente. Amigo, 2020

\begin{tabular}{|l|l|l|}
\hline \multicolumn{1}{|c|}{$\mathrm{Re}=$} & \multicolumn{1}{|c|}{ Ex= } & \multicolumn{1}{c|}{ Oe } \\
\hline $\begin{array}{l}\text { Requerimientos de los } \\
\text { clientes }\end{array}$ & $\begin{array}{l}\text { Expectativa de los } \\
\text { clientes }\end{array}$ & Oferta de la empresa \\
\hline
\end{tabular}

\section{EL PASE DE LOS CIRCULOS DE INFLUENCIA SOCIAL A LOS CÍRCULOS DE AISLAMIENTO SOCIAL}

Las teorías tradicionales sobre comportamiento del consumidor, analizaban que las marcas construían sus procesos de posicionamiento a partir de un individuo que se formaba y vivía con y en su familia, a la que se le agregaban los distintos círculos de influencia social, los que eran utilizados por las marcas para movilizar los hábitos comportamentales, para generar alto impacto en la facturación de la empresa, como era: la familia, los grupos de pertenencia, (grupos en los que el individuo actúa y pertenece, como el club, los amigos, los grupos de trabajo, los grupos de estudio); los grupos de referencia, que son los grupos de los que la persona no forma parte, pero quisiera hacerlo y que eran utilizados por las marcas, para influenciar la decisión de compra y uso, hacia una u otra opción de compra a través de la comunicación, directa e indirecta.

Sobre los grupos de referencia, por último las clases sociales, las culturas y las subculturas determinaban el panel de colores sobre las diversas oportunidades de las marcas, para generar campañas de desarrollo de mercado cualitativo y penetración de mercado.

A partir de la pandemia mundial y el aislamiento consecuente preventivo, la pandemia, se construye como nudo central, sobre la que la única vacuna es el aislamiento, el que se origina en el hogar, y en el que se está produciendo la gran transformación comportamental. Es entonces, en este escenario en donde las marcas deberán redefinir su negocio, sobre la base de variables blandas que unan a los mercados, anteponiéndose a la teoría tradicional de la segmentación por criterios generales y específicos.

Los criterios subjetivos y ad hoc permitirán sustentar la fidelidad de los clientes, sobre la base del verdadero conocimiento de sus requerimientos y expectativas. 


\section{GRÁFICO NÚMERO 11. LOS NUEVOS CÍRCULOS DE INFLUENCIA SOCIAL.}

Fuente: Amigo.2020

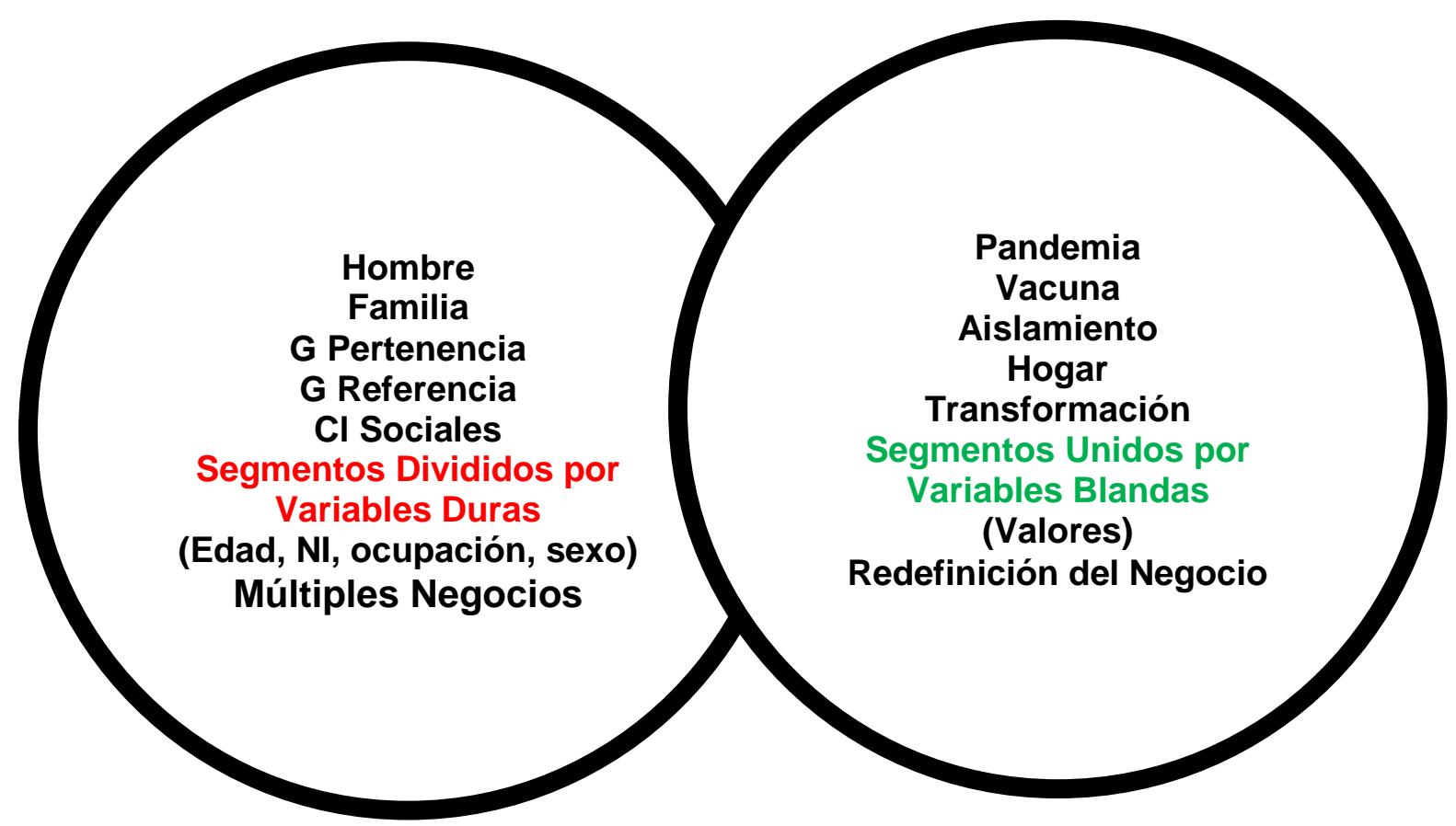

\section{CONCLUSIONES}

- La nueva ecuación del valor, deberá priorizar qué nuevos requerimientos se plantearán a partir de estas nuevas realidades en las que el avala de la comunidad científica será fundamental para que los vínculos entre los clientes y las marcas se gestionen sobre la confiabilidad.

- La nueva comunicación: la sociedad necesita confiar y esa confianza deberá construirse sobre la verdad y la genuina información: "Que la normalidad que añoramos ya no sea contada por los creativos publicitarios, como cuentos de hadas". Los mensajes ya no ganarán por creativos, deberán tener el aval de la comunidad científica.

- En esta crisis, es imprescindible tener un anclaje con el cliente, que agregue valor y trascienda al precio

- En esta crisis, el escenario de vulnerabilidad desde la salud y desde la economía enfrenta a las empresas a un nuevo consumidor, racional y reflexivo que ya no tiene capacidad de decisión indiscriminada y emotiva.

- Los cambios en los estímulos genuinos de satisfacción, determinan un comportamiento en los mercados en un camino racional de solución de 
problemas, en el que la mejor decisión es el resultado de un proceso de evaluación de alternativas.

- El anclaje, lo desarrollará, la construcción ética de la propuesta de valor

- Las marcas se deberán hacer cargo de sus fórmulas de satisfacción

- Si el consumidor no puede confiar, no va a pagar nada. Encontrar Clientes para los productos, ya no será suficiente. Será imprescindible, construir valor para los clientes

- Las empresas que no puedan ser creíbles para sus clientes, perderán el control de su estrategia.

- Estamos frente a una nueva sociedad, un nuevo consumidor, una nueva normalidad y nuevos códigos de interacción social, los que nos plantean una nueva empresa, más humanizada, más empática con el cliente interno y con el cliente externo, con las personas, más solidaria, que encuentre en los nuevos escenarios de crisis, la inspiración para construir valor tan solo monitoreando, interpretando y respetando los nuevos requerimientos sociales e individuales.

- Ante una sociedad en transformación, en la que se está replanteando y cuestionando los modelos de interacción, aparece una sociedad que requerirá valores como la ética, la justicia, la inclusión, la nobleza, la solidaridad, la coparticipación, la responsabilidad individual y colectiva, los que replantearán los círculos de poder y la cultura organizaciones necesaria y suficiente para el desarrollo de capacidades distintivas, en las que se sostendrá la nueva ventaja competitiva sostenible.

\section{REFERENCIAS BIBLIOGRÁFICAS:}

Amigo, Adriana (2009; 2012): Negocios con Valor. Fundación Ross, $1^{\circ}$ y $2^{\circ}$ Ed Argentina.

Amigo, Adriana (2017): Negocios con Valor. Editorial Académica Española, EAE. Edición Europea. Madrid. España

Carrión Maroto, Juan. (2006): Estrategia. De la Visión a la acción. ESIC. 2 • Edición. Madrid. España.

Corzo, Sebastián. (2020). ADN 2020 + Del consumidor Argentino. División Insights. Kartan. Buenos Aires. 2020.

Daft, Richard. (2010): Teoría y diseño organizacional. 10ํㅡdición. México: Cengage Learning. 
Foucault Michel. (1992) Microfísica del poder. Ediciones de la Piqueta. $3^{\circ}$ Edición. Madrid. España

Robbins, Stephen y Coulter, Mary. (2005): Administración. Pearson Educación. $8^{\circ}$ Edición. México.

Schein, Edgard H. (1992): Organizational Culture And Leadership. John Wiley \& Son In. 5² Edición. New Jersey. EE.UU. Última visita 15-9-2020

\section{Páginas y Sitios Webs:}

https://www.perfil.com/noticias/internacional/zygmunt-bauman-ser-populista-no-essiempre-malo.phtml . (9-1-17). Última visita: 15-9-20

https://es.wikipedia.org/wiki/Pandemia de enfermedad por coronavirus de 2019-2020 Última visita: $15-9-20$

https://www.accenture.com/ar-es/about/company/coronavirus-business-economic-impact$\underline{\text { iconic }}$

https://drive.google.com/file/d/1Sno6m5F0A6pKAy62ozBkacqwtLsFCKY7/view?usp=sharing https://www.accenture.com/ar-es/about/company/coronavirus-systems-resilience https://www.ey.com/es pe/board-matters/encuesta-directorios-covid-19 https://ib.impulsobaires.com 